\title{
Research on Chongqing Higher Education Financial Expenditure Performance
}

\author{
Honglei Zhang ${ }^{1}$, Fengyu Wang ${ }^{1}$, Zhenbo Zang ${ }^{2}$ \\ ${ }^{1}$ College of Finance and Economics, Yangtze Normal University, China; \\ ${ }^{2}$ City College of Science and Technology, Chongqing University, China.
}

Key words: DEA model; malmquist index; fiscal expenditure; operation performance.

\begin{abstract}
This paper has studied and analyzed the performance of fiscal expenditure on higher education in Chongqing Municipality. The relevant data in 2009 2016 are selected to analyze the operation performance of higher education in Chongqing Municipality from the human capital input and fiscal investment, using the SE-DEA model and Malmquist index. It turns out that the total factor productivity (TFP) of higher education in Chongqing Municipality tends to improving year by year, closely related to the technical progress (TP) and technical efficiency (TE), with the most important factor being the TP and the least important the scale effect (SE).
\end{abstract}

\section{Introduction}

In our higher education system, the fiscal expenditure funds are an important source of funding to the construction and development of higher education; as the main user of fiscal expenditure funds, the institutions of higher education will achieve different school-running performances, benefiting from different ways of running schools and different usages of fiscal expenditure funds. Scholars have early studied the performance evaluation problem of higher education. Coons (1971) believed that the government served as the source of investment in higher education, and its ability to employ the fiscal funds would have a marked impact on the educational operation. Barlow (1973) deemed that higher education should be pure public goods, providing education service to the public, and able to bring external benefits in multiple aspects by means of public services, including production and cultural benefits. G Psacharopoulos (1973) employed different methods to study the return on investment of education service providers. Sherman (1980) noticed the unbalance of fiscal appropriation among colleges/universities, making a point that the over-reliance on the government funds for running schools would limit the operation of education. Benson (1985) analyzed the fiscal investment problem in education, presenting an idea that fiscal investment should take into account the equity and efficiency simultaneously; besides equity, the efficiency should be taken into account during the educational operation. Wang, Zheng and Zhao (2011) studied the mutual relations between the financial acts of China's local government and the public education expenditure. Ness and Tandberg (2013) studied the correlation effects of capital expenditure on higher education, using the panel data analysis method. Fowles (2014) utilized the resource dependence theory to study the relations between the sources of revenue in the research institution and the institutional spending on education-related activities. Ding and Zeng (2015) employed the combined method of TOPSIS and information entropy weight (IEW) to analyze the operation performance of colleges/universities subordinate to the Ministry of Education (MOE) in 2002 2011. The results indicated that the colleges/universities in the eastern region performed better than those in the central and western regions, and the comprehensive colleges/universities better than most junior colleges. The R\&D capacity determined the overall performance of colleges/universities to a large extent. Dufrechou (2016) analyzed the efficiency problems of public education expenditure in Latin America, and compared them with those in middle- and high-income countries. Si and Qiao (2017) employed the data envelopment analysis (DEA) method to analyze the basic education performance from the integrated technical efficiency, pure technical efficiency, scale effect, scale revenue and scale elasticity. Nose (2017) studied the driving factor of increase in expenditure on public education, 
which turned out that the institutional features of governing the faculty salaries was a decisive factor to influence the education expenditure.

To sum up, it can be seen that scholars have done a lot of research in the expenditure performance of fiscal funds for higher education, but they paid too much attention to the selection and construction of evaluation indexes, and failed to make more comprehensive consideration to the inputs and outputs of educational activities, resulting in the too narrow scope of performance evaluation, and unable to evaluate more efficiently and synthetically the process of using the fiscal expenditure on higher education. In the study, this paper further allows for the inputs and using process of fiscal funds on higher education, to analyze the performance of higher education from the fiscal investment and human capital input. Different from the DEA model by scholars for static performance analysis in the past, the SE-DEA model has solved the problem that the traditional DEA model fails to measure the efficiency comparison of decision-making units (DMUs) after achieving the optimal performance, and is widely used in practice. Allowing for the dynamic performance problem of higher education in the process of operation, this paper has selected the SE-DEA model and Malmquist index to more completely analyze the output performance of higher education by synthesizing the fiscal investment and human capital input. The related structure is arranged as follows: Section II is an introduction to the SE-DEA model and Malmquist index, Section III the empirical analysis and Section IV the research conclusion.

\section{Performance Evaluation Model of Higher Education}

In regard to the unit performance analysis method, the most commonly used is the data envelopment analysis (DEA) method proposed by operations researchers Charnes et al.; so far, the DEA method has become an important evaluation method to analyze the operation performance of multi-input units. The DEA method builds the unit production possibility set and unit input decision portfolio, with the minimum input of unit (or maximum output of unit) as the set boundary to seek the most efficient investment decision for the unit. Suppose that a unit has $\mathrm{n}$ decision-making unit(s) ( $D M U_{j}$ ), where $j=1,2, \ldots, n$, then the vectors of input decision and output decision for the unit are $x_{j}^{T}=\left(x_{1 j}, x_{2 j}, \ldots, x_{m j}\right)$ and $y_{j}^{T}=\left(y_{1 j}, y_{2 j}, \ldots, y_{s j}\right)$ respectively, where $x_{j} \geq 0, y_{j} \geq 0$. The DEA model of such unit is expressed as (1):

$$
\begin{aligned}
& \min \quad \theta-\varepsilon\left(\hat{e}^{T} s^{-}+e^{T} s^{+}\right) \\
& \text {s.t. }\left\{\begin{array}{l}
\sum_{j=1}^{n} \lambda_{j} x_{j}+s^{-}=\theta x_{0} \\
\sum_{j=1}^{n} \lambda_{j} y_{j}-s^{+}=Y_{0} \\
\lambda_{j} \geq 0, j=1,2, \ldots, n \\
s^{-} \geq 0, s^{+} \geq 0
\end{array}\right.
\end{aligned}
$$

Where $\theta$ denotes the operation performance of different DMUs, the larger the $\theta$ value, the higher the operation performance of a DMU. If $\theta_{j}<1$, it indicates that the jth unit fails to achieve the optimal operation performance; if $\theta_{j}=1$, it indicates that the jth unit has achieved the optimal operation performance. Here, $\varepsilon$ is non-Archimedean infinitesimal, $\hat{e}=(1,1,1, \ldots, 1) \in R^{m}, e=(1,1,1, \ldots, 1) \in R^{s}$, $s^{-}$and $s^{+}$denote the input and output relaxation matrixes respectively, $\lambda_{j}$ is the decision planning variable, and $x_{j}, y_{j}$ are the input and output matrixes of the jth DMU respectively.

The traditional DEA model can be used to describe the operational efficiency of an invalid DMU with a numerical value of smaller than 1 , but fails to describe effectively the operational efficiency of multiple efficient DMUs. In the research on the DEA model, the SE-DEA model can be used to fill this gap effectively, able to compare more effectively the operation performance of higher education 
with multiple efficient DMUs. Therefore, this paper has selected the SE-DEA model to analyze the operation performance of higher education. Those numerical values of greater than 1 represent the efficiency values of efficient DMUs, and the efficiency values of invalid units coincide with the representation methods of the typical DEA model. Then, the SE-DEA model allowing for multiple efficient DMUs is expressed as (2):

$$
\text { s.t. }\left\{\begin{array}{c}
\min \theta-\varepsilon\left(e^{T} s^{-}+e^{T} s^{+}\right) \\
\sum_{j=1, j \neq k}^{n} \lambda_{j} x_{j}+s^{-}=\theta x_{k} \\
\sum_{j=1, j \neq k}^{n} \lambda_{j} y_{j}-s^{+}=x_{k} \\
\lambda_{j} \geq 0, j=1,2, \ldots, n \\
s^{-} \geq 0, s^{+} \geq 0
\end{array}\right.
$$

Where $\theta$ still denotes the operation performance of different DMUs, which is a vector made up of the distances from different DMUs to the efficient frontier performance surface; the larger the $\theta$ value, the higher the operation performance of a DMU. If $\theta_{j}<1$, it indicates that the jth DMU fails to achieve the optimal operation performance; if $\theta_{j}=1$, it indicates that the jth DMU has achieved the optimal operation performance. If $\theta_{j}>1$, it indicates the jth DMU has exceeded the optimal operation performance. Here, $\varepsilon$ is non-Archimedean infinitesimal, $\hat{e}=(1,1,1, \ldots, 1) \in R^{m}, e=(1,1,1, \ldots, 1) \in R^{s}$, $s^{-}$and $s^{+}$denote the input and output relaxation matrixes respectively, $\lambda_{j}$ is the planning decision variable, and $x_{j}, y_{j}$ are the input and output matrixes of the jth DMU respectively.

In the research related to the DEA model, the Malmquist index is usually used to describe the operational efficiency of a DMU, Fare et al (1989) has employed the Malmquist index to further decompose the operational efficiency of DMUs into TE change, TP and scale effect change, providing a more powerful tool to analyze the dynamic performance of DMUs. Suppose that the input and output indexes of a DMU at $t$ are $x^{t}$ : and $y^{t}$, the production possibility set $S^{t}$ is used to represent the feasible input and output sets of the DMU at t. Suppose at s, the output distance of the DMU with respect to the possibility set $S^{t}$ at $t$ is expressed as:

$$
D^{t}\left(x^{s}, y^{s}\right)=\inf \left\{\sigma \mid\left(x^{s}, y^{s} / \sigma\right) \in S^{t}\right\}
$$

Then, the Malmquist indexes of the DMU at $t$ and $t+1$ are respectively expressed as:

$$
\begin{gathered}
M_{t}\left(x^{t}, y^{t}, x^{t+1}, y^{t+1}\right)=\frac{D^{t}\left(x^{t+1}, y^{t+1}\right)}{D^{t}\left(x^{t}, y^{t}\right)} \\
M_{t+1}\left(x^{t}, y^{t}, x^{t+1}, y^{t+1}\right)=\frac{D^{t+1}\left(x^{t+1}, y^{t+1}\right)}{D^{t+1}\left(x^{t}, y^{t}\right)}
\end{gathered}
$$

Further, the Malmquist index of the DMU from $t$ to $t+1$ is expressed as the geometric mean of Malmquist indexes at $t$ and $t+1$, namely the Formula (4):

$$
\begin{aligned}
& M_{t, t+1}\left(x^{t+1}, y^{t+1}, x^{t}, y^{t}\right)=\sqrt{M_{t} M_{t+1}} \\
& =\sqrt{\frac{D^{t}\left(x^{t+1}, y^{t+1}\right)}{D^{t}\left(x^{t}, y^{t}\right)} \frac{D^{t+1}\left(x^{t+1}, y^{t+1}\right)}{D^{t+1}\left(x^{t}, y^{t}\right)}}
\end{aligned}
$$

The Malmquist index is also known as the total factor productivity (TFP) index, which is further decomposed into the product of two indexes, i.e. technical progress (TP) and technical efficiency (TE). Of which, the TP index represents the change in technical levels of a DMU, indicating the movement of the DMU production possibility boundary; the TE index is further expressed as the 
product of pure technical efficiency (PE) and scale efficiency (SE), which are used to analyze the source of changes in the TE index of the DMU. This paper has selected the SE-DEA model and the Malmquist index to analyze the changes in the fiscal expenditure performance of higher education in Chongqing Municipality.

\section{Empirical Analysis}

\subsection{Index Selection and Data Source.}

This paper first establishes the first-grade indexes for evaluating the operation performance of fiscal funds on higher education, which are human resources input and fiscal investment, used to show the inputs of human capital and operation capital in Chongqing's higher education. Then, the human resources input is further decomposed into three second-grade indexes, including the proportion of undergraduates in total students, gross enrollment rate \& net enrollment rate and the student-teacher ratio; the fiscal investment is decomposed into three second-grade indexes, including total expenditure on education, financial education expenditure and the proportion of educational expenditure from national finance in national income GDP. The employment rate is selected as the first-grade index to evaluate the operation performance results of fiscal funds on higher education. The 2009 2016 data related to the financial investment in higher education in Chongqing Municipality are selected for the purpose of empirical research. Such data are from the author's visit and investigational study as well as the data collection of statistical yearbooks. Table 1 shows the relevant data of the index system.

Table 1. Fiscal Evaluation Index System for Higher Education

\begin{tabular}{|c|c|c|c|c|c|c|c|c|c|}
\hline $\begin{array}{l}\text { First-grade } \\
\text { index }\end{array}$ & Second-grade index & 2009 & 2010 & 2011 & 2012 & 2013 & 2014 & 2015 & 2016 \\
\hline \multirow{3}{*}{$\begin{array}{l}\text { 1. Human } \\
\text { resources } \\
\text { input }\end{array}$} & $\begin{array}{c}\text { 1.1 Proportion of } \\
\text { undergraduates in total } \\
\text { students }\end{array}$ & $10.80 \%$ & $12.18 \%$ & $18.3 \%$ & $14.20 \%$ & $17.99 \%$ & $16.2 \%$ & $19.97 \%$ & $14.33 \%$ \\
\hline & $\begin{array}{c}1.2 \text { Gross enrollment rate \& } \\
\text { net enrollment rate }\end{array}$ & $30 \%$ & $26.5 \%$ & $32.0 \%$ & $34.10 \%$ & $46.35 \%$ & $37.4 \%$ & $40.5 \%$ & $40.5 \%$ \\
\hline & 1.3 Student-teacher ratio & $5.49 \%$ & $4.36 \%$ & $3.3 \%$ & $5.33 \%$ & $3.6 \%$ & $3.47 \%$ & $5.2 \%$ & $4.75 \%$ \\
\hline \multirow{3}{*}{$\begin{array}{c}2 . \\
\text { Financial } \\
\text { investment }\end{array}$} & $\begin{array}{l}\text { 2.1 Total expenditure on } \\
\text { education }\end{array}$ & $\begin{array}{c}330.4935 \\
\text { Billion } \\
\text { RMB } \\
33.04935 \\
\text { billion }\end{array}$ & $\begin{array}{c}223.6948 \\
\text { Billion } \\
\text { RMB } \\
22.36948 \\
\text { billion }\end{array}$ & $\begin{array}{c}214.1932 \\
\text { Billion } \\
\text { RMB } \\
21.41932 \\
\text { billion }\end{array}$ & $\begin{array}{c}663.3953 \\
\text { Billion } \\
\text { RMB } \\
66.33953 \\
\text { billion } \\
\end{array}$ & $\begin{array}{c}656.562 \\
\text { Billion } \\
\text { RMB } \\
65.6562 \\
\text { billion }\end{array}$ & $\begin{array}{c}469.9807 \\
\text { Billion } \\
\text { RMB } \\
46.99807 \\
\text { billion }\end{array}$ & $\begin{array}{c}689.4300 \\
\text { Billion } \\
\text { RMB } \\
68.943 \\
\text { billion } \\
\end{array}$ & $\begin{array}{c}270.1912 \\
\text { Billion } \\
\text { RMB } \\
27.01912 \\
\text { billion }\end{array}$ \\
\hline & $\begin{array}{l}2.2 \text { Financial education } \\
\text { expenditure }\end{array}$ & $\begin{array}{c}240.4608 \\
\text { Billion } \\
\text { RMB } \\
24.04608 \\
\text { billion } \\
\end{array}$ & $\begin{array}{c}235.8418 \\
\text { Billion } \\
\text { RMB } \\
23.58418 \\
\text { billion } \\
\end{array}$ & $\begin{array}{c}318.7008 \\
\text { Billion } \\
\text { RMB } \\
31.87008 \\
\text { billion } \\
\end{array}$ & $\begin{array}{c}406.58 \\
\text { Billion } \\
\text { RMB } \\
40.658 \\
\text { billion } \\
\end{array}$ & $\begin{array}{c}522.8011 \\
\text { Billion } \\
\text { RMB } \\
52.28011 \\
\text { billion } \\
\end{array}$ & $\begin{array}{c}44.14 \\
\text { Billion } \\
\text { RMB } \\
44.714 \\
\text { billion } \\
\end{array}$ & $\begin{array}{c}453.41 \\
\text { Billion } \\
\text { RMB } \\
45.341 \\
\text { billion } \\
\end{array}$ & $\begin{array}{c}535.4876 \\
\text { Billion } \\
\text { RMB } \\
53.54876 \\
\text { billion } \\
\end{array}$ \\
\hline & $\begin{array}{c}\text { 2.3 Proportion of } \\
\text { educational expenditure } \\
\text { from national finance in } \\
\text { national income GDP }\end{array}$ & $5.67 \%$ & $5.17 \%$ & $3.4 \%$ & $4.28 \%$ & $4.09 \%$ & $4.07 \%$ & $4.57 \%$ & $4.26 \%$ \\
\hline $\begin{array}{l}\text { 3. Output } \\
\text { index }\end{array}$ & 3.1 Employment rate & $92.34 \%$ & $90.6 \%$ & $87.6 \%$ & $84.63 \%$ & $70.1 \%$ & $94.91 \%$ & $92.17 \%$ & $88.98 \%$ \\
\hline
\end{tabular}

\subsection{Empirical Results Analysis.}

In general, the operation performance of DMUs can be analyzed from two aspects, one is selecting the operational data of DMUs and then employing the DEA model to calculate the integrated productivities of DMUs every year, and the other is utilizing the Malmquist index to further decompose the integrated productivities into TP and TE changes, so as to analyze the reasons for changes in the integrated productivities of DMUs from more than one side. This paper first adopts the SE-DEA model to analyze the operation performance of higher education in Chongqing Municipality, and then employs the Malmquist index to analyze such operation performance, in order to find the reasons for performance changes. Table 2 shows the changes in comprehensive technical super-efficiency of higher education in Chongqing Municipality obtained from the analysis with the SE-DEA model, and the decomposition of such comprehensive technical super-efficiency using the Malmquist index. 
Table 2. Changes in the Performance of Fiscal Expenditure on Higher Education in Chongqing Municipality (2009-2016)

\begin{tabular}{|c|c|c|c|c|c|}
\hline Year & $\begin{array}{c}\text { Total factor } \\
\text { productivity (TFP) }\end{array}$ & $\begin{array}{c}\text { Technical } \\
\text { progress (TP) }\end{array}$ & $\begin{array}{c}\text { Technical } \\
\text { efficiency (TE) }\end{array}$ & $\begin{array}{c}\text { Pure technical } \\
\text { efficiency (PE) }\end{array}$ & $\begin{array}{c}\text { Scale } \\
\text { efficiency } \\
\text { (SE) }\end{array}$ \\
\hline 2009 & 0.741 & 0.906 & 0.817 & 0.947 & 0.864 \\
\hline 2010 & 0.924 & 0.894 & 1.033 & 1.037 & 0.997 \\
\hline 2011 & 1.103 & 1.062 & 1.038 & 0.943 & 1.101 \\
\hline 2012 & 0.975 & 0.937 & 1.040 & 0.976 & 1.066 \\
\hline 2013 & 1.056 & 0.901 & 1.172 & 1.317 & 0.890 \\
\hline 2014 & 0.843 & 1.171 & 0.719 & 1.201 & 0.559 \\
\hline 2015 & 0.927 & 0.934 & 0.992 & 0.924 & 1.074 \\
\hline 2016 & 1.003 & 0.921 & 1.089 & 1.314 & 0.829 \\
\hline Mean & 0.947 & 0.966 & 0.988 & 1.082 & 0.928 \\
\hline
\end{tabular}

It can be seen from Table 2 that in the 8 years from 2009 to 2016, Chongqing's institutions of higher education have their comprehensive technical super-efficiency exceed 1 in 3 years, and not exceed 1 in the other 5 years; the comprehensive technical super-efficiency reaches its maximum of 1.103 in 2011, and the minimum of 0.741 in 2009. It can be seen that the operational efficiency of higher education in Chongqing Municipality still tends to improving year by year regardless of its failure to exceed 1 every year. Table 2 shows also the decomposition index of TFP of Chongqing's institutions of higher education from 2009 to 2016.

To more intuitively analyze the changes in the operational efficiency of higher education in Chongqing Municipality, we utilize the relevant data in Table 1 to draw Fig. 1 for the purpose of comparative analysis. Fig. 1 shows the changes in TFP, TP and TE of Chongqing's institutions of higher education from 2009 to 2016. It can be seen from Fig. 1 that TFP keeps basically consistent with the changes of TP and TE from 2009 to 2011, indicating the changes of TP and TE are closely correlated with the change of TFP in these years. From 2011 to 2014, TFP keeps basically consistent with the change of TE, but not very consistent with that of TP, which indicates that the TFP change is mainly dominated by that of TE during this period, and such guiding feature is especially apparent in 2014. In 2015 2016, TFP keeps basically consistent with the changes of TP and TE, indicating that the improvement of TFP benefits from the common improvement of TP and TE.

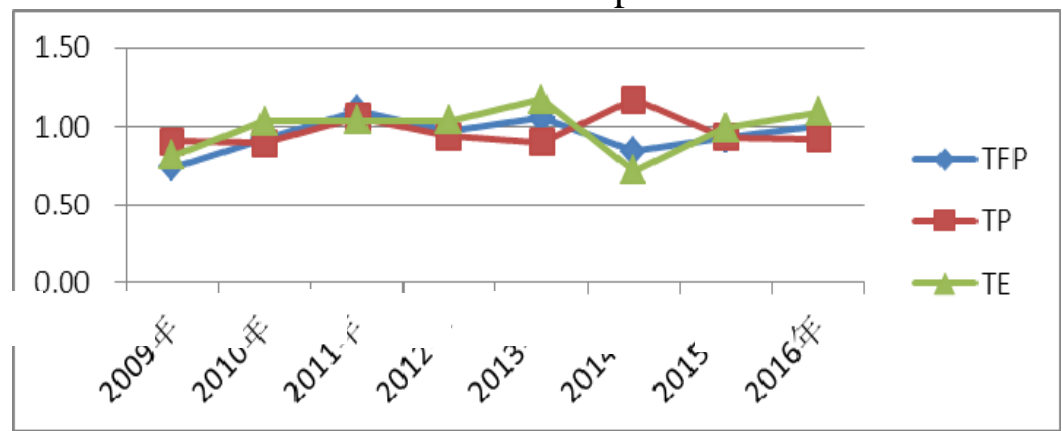

Fig 1. TFP Index of Higher Education in Chongqing Municipality and Its Decomposition Trend

It can be seen from the change trend of TFP that the changes in TFP of higher education in Chongqing Municipality are mainly determined jointly by TP and TE changes, among which the TP has played a significant leading role. TP has changed the operational efficiency of DMUs, facilitating more outputs on the same input conditions. 


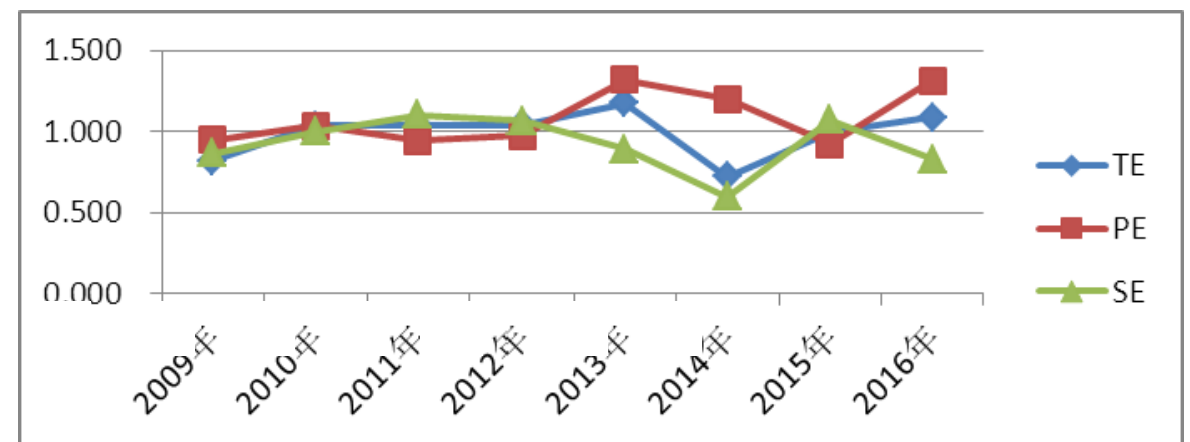

Fig.2 TE of Higher Education in Chongqing Municipality and Its Decomposition Trend

Since TE $=\mathrm{PE} * \mathrm{SE}$, this paper has further decomposed the TE to analyze more comprehensively the source of TFP changes. Fig. 2 shows the changes in TE, PE and SE of higher education structure in Chongqing Municipality from 2009 to 2016, with TE jointly determined by PE and SE; it can be seen from Fig. 2 that in 2009-2014 and 2015-2016, TE keeps roughly consistent with the changes of PE and SE, indicating the strong correlation between the PE \& SE and the changes of TE during these years. Moreover, in 2013-2014, TE shows a downward trend, while PE and SE descend at a larger percentage as well, indicating $\mathrm{PE}$ and SE co-determine the changes of TE at this stage. However, in 2014-2015, the changes of PE and SE deviate somewhat from those of TE, in which, the SE values are greater than TE values, indicating TE changes rely mainly on SE during this period, and the operation of higher education is in the stage of quantitative development. It can be seen from the data above that the operational efficiency of tertiary institutions in Chongqing Municipality vary with different years, and smaller than 1 in a certain period, plus the TFP changes are determined by multiple factors; hence, the operational efficiency of higher education in Chongqing Municipality must be improved in many ways, for the rational and effective use of all resources.

\section{Research Conclusion}

This paper has studied the dynamic operation performance of higher education in Chongqing Municipality, and selected relevant data in 2009-2016 to analyze the operation performance of higher education in Chongqing Municipality from human capital input and fiscal investment, using the SE-DEA model and the Malmquist index. This paper has drawn main conclusions as follows: first, based on the analysis with the SE-DEA model, we found that in 2009-2016, the higher education in Chongqing Municipality is characterized by a general level of comprehensive super-efficiency, which fails to exceed 1 in five years, indicating that the operation performance of tertiary institutions still can be improved so much more. Meanwhile, the comprehensive super-efficiency level has been improved year by year in these 8 years, which indicates that the operation performance of higher education in Chongqing Municipality can be steadily enhanced by improving the governance structure and the allocation of educational resources of tertiary institutions, in spite of the existing low performance level of higher education in Chongqing Municipality.

Second, based on the analysis using the Malmquist index, we have found that in 2009-2016, TFP keeps roughly consistent with the changes of TP and TE, which indicates that the improvement of TFP benefits from the common changes in TP and TE during this period. Compared with TP, the TE changes have a greater impact on TFP. To better analyze the factors affecting the TFP changes, this paper has further decomposed TE into PE and SE. The study shows that in 2009-2016, TE keeps roughly consistent with the changes of $\mathrm{PE}$ and $\mathrm{SE}$, of which $\mathrm{PE}$ has a greater impact on TE in comparison with SE. With the study, we can basically come to the conclusions: regardless of the existing low operational efficiency, the overall operation performance of higher education in Chongqing Municipality can be enhanced by effectively changing the school-running models and the fund utilization efficiency, in which the TE promotion is an important way to improve the operational efficiency, while the SE has a little effect on the operational efficiency of higher education, and it is relatively insignificant. This paper has enlightened us that the construction of higher education must follow connotative development, in pursuit of internal governance structure and enhancement of 
school-running means as well as the maximum utilization efficiency of fiscal funds, so as to improve the overall TE of school runners, rather than blind pursuit of school sizes. Therefore, we should, in the process of running tertiary institutions, build a well-established teaching system and college/university governance structure, lay emphasis on the introduction of advanced education ideas and methods, and utilize the advanced teaching techniques to promote the higher teaching efficiency; we should further focus on the construction and training of faculty, endeavor to improve the teaching ability of teachers, and refuel the teaching approach of linking theories with practices; besides, we should do well in the budget for utilization of fiscal funds, and effectively raise the utilization level of fiscal funds following the goal of maximizing the operation performance.

\section{Acknowledgements}

The authors thanks the support of the Chunhui Project Cooperation Research Project of the Ministry of Education (Grant No: S2015060); the support of Advanced Education Scientific Research Project of Chongqing Higher Education Society (Grant No: CQGJ13B342); the support of Chongqing Education Science Planning Project (Grant No: 2014-GX-043).

The authors thanks the support of the Science and Technology Research Program of Chongqing Municipal Education Commission (Grant No: KJ1709235); the support of Chongqing Social Science Planning PhD Program (Grant No: 2016BS115).

\section{References}

[1]. [1] Douglass H R. Private Wealth and Public Education by John E. Coons; William H. Clone; Steven B. Sugar man [J]. Journal of Educational Research, 1971(3):131.

[2]. Barlow R. Efficiency Aspects of Local School Finance: Reply. [J]. Journal of Political Economy, 1973, 81(Volume 81, Number 1):199-202.

[3]. Psacharopoulos G, Hinchliffe K. Returns to Education: An International Comparison. Studies on Education; Vol. 2. [J]. Comparative Education Review, 1973, 11(Volume 17, Number 3):131.

[4]. Sherman J D. Equity in School Finance: A Comparative Case Study of Sweden and Norway. [J]. Comparative Education Review, 1980, 24(Volume 24, Number 3):389-399.

[5]. Benson C S. The public school monopoly: a critical analysis of education and the state in American society: Edited by R B. E. Cambridge, MA: Ballinger, 1982. pp. 583. No price given [J]. Economics of Education Review, 1985, 4(2):145-146.

[6]. Wang W, Zheng X, Zhao Z. Fiscal reform and public education spending: A quasi-natural experiment of fiscal decentralization in China [J]. Publics: The Journal of Federalism, 2011, 42(2): 334-356.

[7]. Ness E C, Tandberg D A. The determinants of state spending on higher education: How capital project funding differs from general fund appropriations [J]. The Journal of Higher Education, 2013, 84(3): 329-362.

[8]. Fowls J. Funding and focus: Resource dependence in public higher education [J]. Research in Higher Education, 2014, 55(3): 272-287.

[9]. Ding L, Zeng Y. Evaluation of Chinese higher education by TOPSIS and IEW-the case of 68 universities belonging to the Ministry of Education in China [J]. China Economic Review, 2015, 36: 341-358.

[10]. Dufrechou P A. The efficiency of public education spending in Latin America: A comparison to high-income countries [J]. International Journal of Educational Development, 2016, 49: 188-203. 
[11]. Si L B, Qian H Y. Performance of Financial Expenditure in China's basic science and math education: Panel Data Analysis Based on CCR Model and BBC Model [J]. EURASIA Journal of Mathematics, Science and Technology Education, 2017, 13(8): 5217-5224.

[12]. Nose M. Estimation of drivers of public education expenditure: Baume's effect revisited [J]. International Tax and Public Finance, 2017, 24(3): 512-535. 